\title{
Nanoscale Lipidic Carrier Systems: Importance of Preparation Method and Solvents
}

\author{
Mozafari MR*, Danaei M, Javanmard R, Raji M and Maherani B \\ *Australasian Nanoscience and Nanotechnology Initiative, Australia
}

Submission: July 13, 2017; Published: August 02, 2017

*Corresponding author: MR Mozafari, Australasian Nanoscience and Nanotechnology Initiative, Australia, Research Laboratories in Sciences Applied to Food, Canadian Irradiation Centre, INRS-Institute Armand- Frappier, Canada, Email: dr.m.r.mozafari@gmail.com

\begin{abstract}
Nanoscale lipidic carrier systems have crucial role in drug delivery, drug targeting, diagnostics and nanotherapy. These systems include liposome, nanoliposome, archaeosome, vesicular gels and more recently introduced tocosome. They can accommodate water-soluble material in their aqueous compartment(s) and, if required simultaneously, lipid-soluble substances in their lipid phases. There are already a number of approved liposomal and nanoliposomal products on the market for Human use. However, in order to improve the quality, shelf-life and safety of these products, it is necessary to pay particular attention to the choice of manufacturing method and especially selection of solvents and cosolvents. This entry will focus on the importance of preparation methods and solvents in the manufacture of lipidic nanocarriers.
\end{abstract}

Keywords: Liposome; Mozafari Method; Nanoliposome; Nanotechnology; Polar aprotic solvents; Tocosome

\section{Introduction}

Nano-encapsulation involves the incorporation of bioactive material, including therapeutic compounds, diagnostic agents, vitamins, antioxidants, enzymes, nutraceuticals and cosmetic material, in small vesicles with submicron diameters. Lipid-based nanocarriers, which have been developed for drug delivery and encapsulation applications, include different systems such as liposome, nanoliposome, archaeosome, vesicular phospholipid gels and tocosome [1,2]. The main ingredients of lipidic carriers comprise lipid and/or phospholipid molecules. However, these carriers may also contain sterols and/or antioxidants in their structure [3]. The most commonly used sterol in the formulation of lipidic carriers is cholesterol, which leads to increasing the stability of the vesicles by modulating the fluidity of the lipid components [4].

Compared with other encapsulation techniques, such as polymeric nanoparticles, chitosan- and alginate-based carriers, lipid-based carrier systems have many advantages, including the ability to entrap material with different solubility, the possibility of being produced using natural ingredients on an industrial scale, and targetability [3]. Lipid-based carriers can protect the encapsulated material from free radicals, metal ions, $\mathrm{pH}$ and enzymes that might otherwise result in the degradation of the active compound. They provide stability to water-soluble ingredients, particularly in high water-activity applications. They can encapsulate or entrap not only water-soluble material but also lipid-soluble compounds simultaneously, providing a synergistic effect. Another unique property of lipidic carriers is the targeted delivery of their content to the required site inside the body via active (e.g. by incorporation of antibodies) and passive (e.g. targeting based on particle size) mechanisms [5].

\section{Manufacturing methods of lipidic carriers}

There are a wide variety of conventional and new methods, which can be used to produce lipid-based carriers. Selection of a suitable preparation technique is not arbitrary and depends on the following parameters:

a. physicochemical properties of the medium/solvents/ co-solvents in which the precursors and the resultant lipidic carriers are suspended

b. desired shelf-life, drug release profile, optimum size, and polydispersity of the vesicles

c. potential toxicity and effective concentration of substances which are intended to be encapsulated or entrapped in the lipidic carriers [6,7]. 


\section{Global Journal of Nanomedicine}

There are several laboratory-scale and a few large-scale techniques for lipidic carrier preparation. These methods give rise to vesicles of different sizes ranging from $20 \mathrm{~nm}$ to several micrometers in diameter and composed of one or more bilayers [8]. However, most of these methods are not suitable for the encapsulation of sensitive and fragile material because of their exposure to mechanical stress (e.g. sonication, high-shear force homogenisation, or high pressures), potentially harmful chemicals (e.g. volatile organic solvents and detergents) or extreme levels of $\mathrm{pH}$. Table 1 lists some of the commonly used methods of lipidic carrier manufacture with their advantages and limitations.

Table 1: Advantages and disadvantages of some of the commonly used preparation methods of lipidic carriers $[4,5,8]$.

\begin{tabular}{|c|c|c|}
\hline Method & Advantages & Disadvantages \\
\hline Bangham (Thin-layer hydration method) & Simple method & $\begin{array}{l}\text { Use of potentially toxic solvents, time } \\
\text { consuming, difficult to scale-up }\end{array}$ \\
\hline Ethanol/ether injection & Simple procedure & $\begin{array}{l}\text { Organic solvent residue, nozzle blockage in } \\
\text { ether system, time consuming, sterilization } \\
\text { issue }\end{array}$ \\
\hline Reverse phase evaporation & $\begin{array}{c}\text { Simple design, acceptable encapsulation } \\
\text { efficiency }\end{array}$ & $\begin{array}{c}\text { Not suitable for the encapsulation of sensitive } \\
\text { material due to large quantity of organic } \\
\text { solvent use, time consuming, sterilization } \\
\text { issue }\end{array}$ \\
\hline Microfluidisation & $\begin{array}{c}\text { Control of particle size, large volume } \\
\text { manufacture in a continuous and reproducible } \\
\text { manner }\end{array}$ & $\begin{array}{l}\text { Employment of high pressures (up to } 10,000 \\
\text { psi) }\end{array}$ \\
\hline Supercritical Fluid Process & $\begin{array}{l}\text { Control of particle size, possible in situ } \\
\text { sterilization, low organic solvent consumption }\end{array}$ & $\begin{array}{l}\text { High cost, low yield, high pressure up to } 350 \\
\text { bar used }\end{array}$ \\
\hline Dual asymmetric centrifugation & $\begin{array}{l}\text { Simple method, yields products with narrow } \\
\text { size distribution, high encapsulation efficiency }\end{array}$ & $\begin{array}{l}\text { Not suitable for bulk production, high } \\
\text { pressure and high shear force }\end{array}$ \\
\hline Sonication & Simple and fast technique & $\begin{array}{l}\text { Overheating of the lipid suspension causing } \\
\text { degradation, sonicator tips release metal } \\
\text { particles into the product }\end{array}$ \\
\hline Mozafari Method & $\begin{array}{l}\text { Simple design, safe and mild procedure, } \\
\text { organic solvent free, easily scalable }\end{array}$ & $\begin{array}{l}\text { New method, Reproducibility need to be } \\
\text { attested under various conditions }\end{array}$ \\
\hline
\end{tabular}

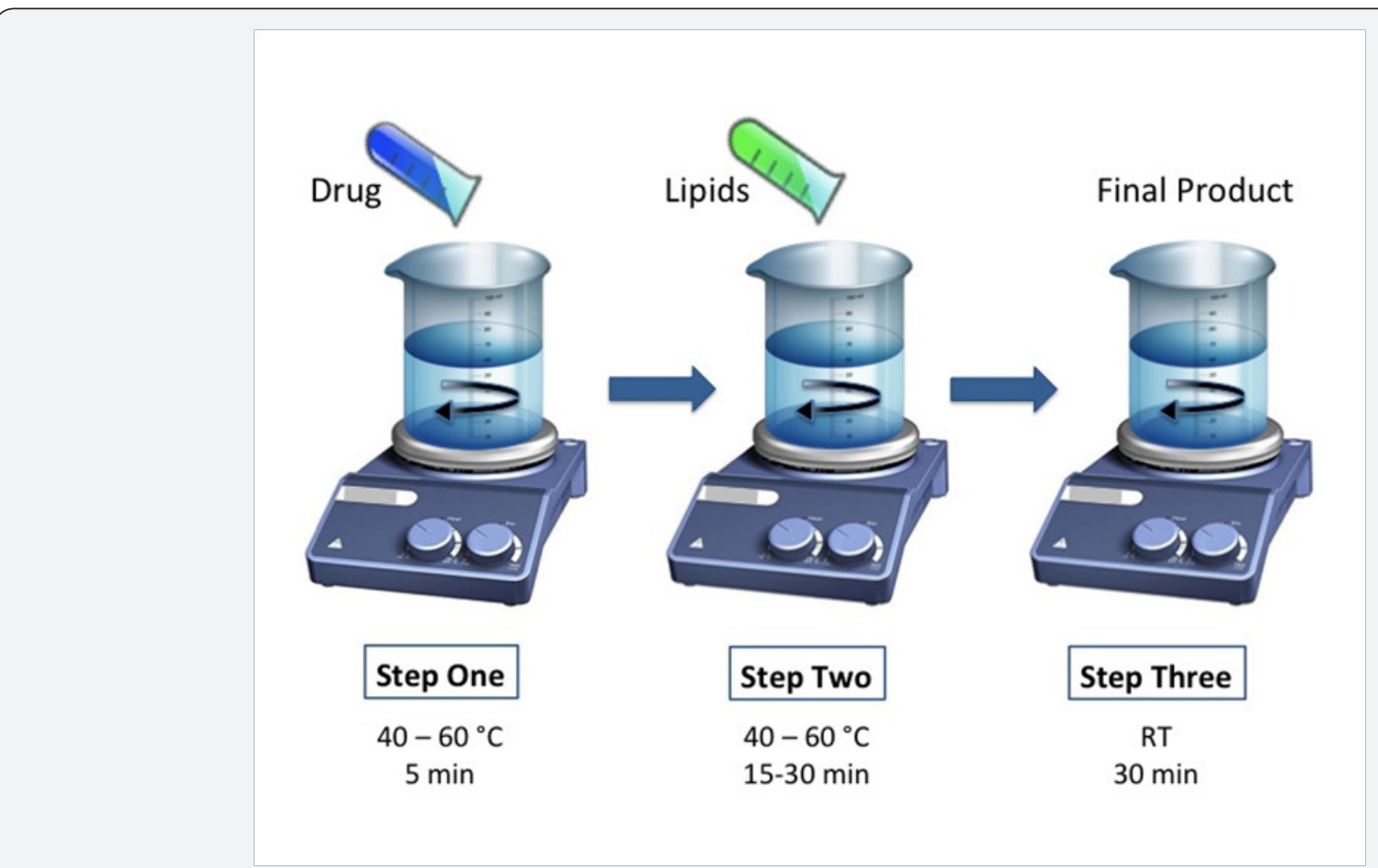

Figure 1: Schematic presentation of steps involved in the manufacture of lipidic carriers using Mozafari Method (RT: room temperature). 
Conventional methods generally involve four basic stages: drying down of lipid/phospholipid ingredients from organic solvents, dispersion of these ingredients in an aqueous media, purification of the resultant vesicles, and analysis of the final product. However, organic solvent residues, remaining in the lipidic and/or aqueous phases of the vesicles during their preparation, could result in toxicity. Application of the volatile organic solvents in lipidic carrier preparation is one of the disadvantages that nearly all conventional manufacture methods suffer from. Recent developments in the field of encapsulation technology have made it possible to prepare lipid vesicles without using any volatile organic solvent or detergent, examples of which are the polyol dilution method [9], the bubble method [10] and the Mozafari method developed in our laboratory (Figure 1).

\section{Importance of solvent selection in the manufacture of lipidic carriers}

The organic solvents used in lipidic carrier preparation (e.g. chlorinated solvents, acetone, diethyl ether or methanol), represent a possible risk to human health as well as the environment due to their toxicity. The residual organic solvent that is acceptable in the finished product depends on parameters such as the type of solvent and the route of administration of the pharmaceutical product. Although the organic solvents are usually removed by vacuum or evaporation, traces may be present in the final formulation, potentially causing toxicity and influencing the stability of the product. In order to solve these disadvantages, the use of alternative organic solvents is being considered by scientists and researchers in the field [11]. It has been suggested that organic solvents can cause cellular toxicity via two types of mechanism:

I. At the molecular level, or

II. At the phase level.

The effects caused by organic solvents that are dissolved within the aqueous phase and include enzyme inhibition, protein denaturation and membrane modifications (such as membrane expansion, structure disorders and permeability changes) are examples of molecular level cytotoxicity. Phase toxicity effects, on the other hand, include the extraction of nutrients, disruption of the cell wall (extraction of outer cellular components), and the limited access to nutrients caused by cell attraction to interfaces, the formation of emulsions and the coating of cells. In addition to the above-mentioned disadvantages, application of volatile organic solvents or detergents necessitates performance of two additional steps in the manufacture of lipidic carrier systems:

I. Removal of these solvents/detergents, and

II. Assessment of the level of residual solvents, including the potentially toxic polar and non polar protic and aprotic solvents or detergents remained in the final products.
Consequently, avoiding the utilisation of these solvents/ detergents, e.g. by employing safe and robust procedures such as Mozafari Method, will potentially bring down the time and cost of manufacture of lipid-based encapsulation systems. Mozafari method has been successfully employed for the encapsulation of a number of different nutraceutical and pharmaceutical compounds including the anticancer agent 5-fluorouracil.

\section{Conclusion}

Lipid-based drug delivery systems have shown significant promise in the research and development of new drug entities. Among the main parameters to be considered in the formulation of lipidic carriers, and obtain required regulatory approval for Human use, are the method of preparation and selection of non-toxic solvents in product manufacture. One of the recently developed techniques, which meet these criteria, is Mozafari Method. This method not only avoids employment of toxic solvents, but also is a very simple procedure and can manufacture different encapsulation products in large quantities (industrial scale).

\section{References}

1. Hughes GA (2005) Nanostructure-mediated drug delivery. Nanomedicine 1(1): 22-30.

2. Mozafari MR, Javanmard R, Raji M (2017) Tocosome: Novel drug delivery system containing phospholipids and tocopheryl phosphates. Int J Pharm 528(1-2): 381-382.

3. Mozafari MR, Flanagan J, Matia-Merino L, Awati A, Omri A, et al (2006) Review: recent trends in the lipid-based nanoencapsulation of antioxidants and their role in foods. J Sci Food Agr 86(13): 2038-2045.

4. Mozafari MR (2010) Nanoliposomes: preparation and analysis. Methods Mol Biol 605: 29-50.

5. Maherani B, Arab-Tehrany E, Mozafari MR, Gaiani C, Linder M (2011) Liposomes: a review of manufacturing techniques and targeting strategies. Curr Nanosci 7: 436-452.

6. Oksztulska-Kolanek E (2013) Methods of nanoliposomes preparation Curr Iss Pharm Med Sci 26(2): 203-205.

7. Mozafari MR, Johnson C, Hatziantoniou S, Demetzos C (2008) Nanoliposomes and their applications in food nanotechnology. J Liposome Res 18(4): 309-327.

8. Mozafari MR (2005) Liposomes: an overview of manufacturing techniques. Cell Mol Biol Lett 10(4): 711-719.

9. Kikuchi H, Yamauchi H, Hirota S (1994) A polyol dilution method for mass production of liposomes. J Liposome Res 4(1): 71-91.

10. Talsma H, Van Steenbergen MJ, Borchert JCH, Crommelin DJA (1994) A novel technique for the one-step preparation of liposomes and nonionic surfactant vesicles without the use of organic solvents. Liposome formation in a continuous gas stream: The bubble method. J Pharm Sci 83(3): 276-280.

11. Cortesi R, Esposito E, Gambarin S, Telloli P, Menegatti E, et al. (1999) Preparation of liposomes by reverse-phase evaporation using alternative organic solvents. J Microencapsul 16(2): 251-256. 
(C) (i) This work is licensed under Creative Commons Attribution 4.0 License DOI: $10.19080 / G J N .2017 .02 .555593$

\section{Your next submission with JuniperPublishers} will reach you the below assets

- Quality Editorial service

- Swift Peer Review

- Reprints availability

- E-prints Service

- Manuscript Podcast for convenient understanding

- Global attainment for your research

- Manuscript accessibility in different formats

( Pdf, E-pub, Full Text, Audio)

- Unceasing customer service

Track the below URL for one-step submission https://juniperpublishers.com/submit-manuscript.php 